\title{
Distinct Gamma-Band Evoked Responses to Speech and Non-Speech Sounds in Humans
}

\author{
Satu Palva, ${ }^{1,3}$ J. Matias Palva, ${ }^{2}$ Yury Shtyrov, ${ }^{1,4}$ Teija Kujala,, ${ }^{1}$ Risto J. IImoniemi, ${ }^{1,3}$ Kai Kaila, ${ }^{2}$ and \\ Risto Näätänen ${ }^{1,3}$ \\ ${ }^{1}$ Cognitive Brain Research Unit, Department of Psychology and 2Department of Biosciences, Division of Animal \\ Physiology, FIN-00014 University of Helsinki, Finland, ${ }^{3}$ BioMag Laboratory, Engineering Centre, Helsinki University Central \\ Hospital, FIN-00029 HUS, Finland, and ${ }^{4}$ Cognition and Brain Sciences Unit, Medical Research Council, CB2 2EF, \\ Cambridge, United Kingdom
}

To understand spoken language, the human brain must have fast mechanisms for the representation and identification of speech sounds. Stimulus-induced synchronization of neural activity at gamma frequencies $(20-80 \mathrm{~Hz})$, occurring in humans at 200-300 msec from stimulus onset, has been suggested to be a possible mechanism for neural object representation. Auditory and visual stimuli also evoke an earlier (peak $<100$ msec) gamma oscillation, but its dependence on high-level stimulus parameters and, thereby, its involvement in object representation has remained unclear.

Using whole-scalp magnetoencephalography, we show here that responses evoked by speech and non-speech sounds differed in the gamma-frequency but not in the low-frequency $(0.1-20 \mathrm{~Hz})$ band as early as $40-60 \mathrm{msec}$ from stimulus onset. The gamma-band responses to the speech sound peaked earlier in the left than in the right hemisphere, whereas those to the non-speech sound peaked earlier in the right hemisphere. For the speech sound, there was no difference in the response amplitude between the hemispheres at low (20-45 Hz) gamma frequencies, whereas for the non-speech sound, the amplitude was larger in the right hemisphere. These results suggest that evoked gamma-band activity may indeed be sensitive to highlevel stimulus properties and may hence reflect the neural representation of speech sounds. Consequently, speechspecific neuronal processing may commence no later than 40-60 msec from stimulus onset, possibly in the form of activation of language-specific memory traces.

Key words: evoked gamma oscillation; speech sound; representation; human; magnetoencephalography (MEG); lateralization
Synchronization of neuronal firing, often associated with gammafrequency $(20-80 \mathrm{~Hz})$ oscillations, has been hypothesized to have a critical role in feature binding and thus in the generation of object representations. Indeed, several studies in awake and anesthetized cats, monkeys, and humans have provided evidence for the key role of neural synchrony in feature integration (Singer and Gray, 1995; Gray, 1999; Singer, 1999; Castelo-Branco et al., 2000).

In humans, the functional roles of the evoked (phase locked to stimulus onset) and induced (non-phase locked) gamma oscillations, occurring at 40-100 and 200-300 msec from stimulus onset, respectively, have been studied using visual and auditory stimuli. In accordance with the binding and representational hypotheses, studies with visual stimuli have demonstrated that the amplitude (Lutzenberger et al., 1994; Tallon-Baudry et al., 1996, 1997; Eulitz et al., 2000) and the degree of large-scale synchrony (Rodriguez et al., 1999) of the induced gamma oscillations depend on Gestalt or cognitive stimulus properties such as coherence and meaningfulness. Accordingly, auditory induced gamma oscillations have been shown to reflect, for example, lexical processing

\footnotetext{
Received July 27, 2001; revised Dec. 12, 2001; accepted Dec. 14, 2001.

This work was supported by the Academy of Finland, the Finnish Cultural Foundation, and the Juselius Foundation of Finland. We are grateful to Titia van Zuijen, Klaus Linkenkaer-Hansen, and Ole Jensen for their helpful comments on the previous versions of this manuscript.

Correspondence should be addressed to Satu Palva, BioMag Laboratory, Engineering Centre, Helsinki University Central Hospital, Haartmaninkatu 4, P.O. Box 340, FIN-00029 HUS, Finland. E-mail: satu.palva@helsinki.fi.

Copyright (C) 2002 Society for Neuroscience 0270-6474/02/220001-05\$15.00/0
}

(Pulvermüller et al., 1996). The evoked gamma response, on the other hand, has been reported to be insensitive to such high-level stimulus properties both in the visual (above) and in the auditory modalities (Pantev et al., 1991; Bertrand and Pantev, 1994; Pantev and Elbert, 1994; Tiitinen et al., 1994; Haenschel et al., 2000), although Knief et al. (2000) showed that evoked gamma responses to sounds with regular or irregular harmonic structures differed from each other. It has thus been suggested that the induced gamma oscillations underlie object representation (TallonBaudry and Bertrand, 1999), whereas evidence for a similar role of the evoked oscillations has not been available.

Other lines of research have shown that high-level neural representations of behaviorally relevant stimuli such as phonemes (Näätänen et al., 1997), complex visual scenes (Thorpe et al., 1996), faces (Linkenkaer-Hansen et al., 1998), and visually presented words (Assadollahi and Pulvermüller, 2001; Pulvermüller

This article is published in The Journal of Neuroscience, Rapid Communications Section, which publishes brief, peerreviewed papers online, not in print. Rapid Communications are posted online approximately one month earlier than they would appear if printed. They are listed in the Table of Contents of the next open issue of JNeurosci. Cite this article as: JNeurosci, 2002, 22:RC211 (1-5). The publication date is the date of posting online at www.jneurosci.org.

http://www.jneurosci.org/cgi/content/full/6134 
et al., 2001) are available within 100-150 msec from stimulus onset, only shortly after the termination of evoked gamma oscillations. Here we examine the possibility that the evoked gamma response reflects the generation of early neural object representations, which would be supported by sensitivity of the response to high-level stimulus properties (Tallon-Baudry and Bertrand, 1999). We investigated magnetic evoked responses to a speech sound and to its non-speech acoustical equivalent. Here we show that the evoked responses to these stimuli are distinct in the gammafrequency band in the left and right cerebral hemispheres.

Some of the results presented in this paper have been previously published in abstract form (Palva et al., 2000).

\section{MATERIALS AND METHODS}

Subjects and stimuli. Magnetic responses to speech and complex nonspeech sounds were recorded from 17 healthy, normal-hearing, righthanded native Finnish speakers. The subjects gave their informed consent before their participation in the study. The experiments were performed in accordance with the Declaration of Helsinki and the ethical guidelines of the University of Helsinki. The sound stimuli were plosive semi-synthetic Finnish syllables /pa/ and / ka/ (Alku et al., 1999) and complex non-speech stimuli, each constructed to match both the consonant $(/ \mathrm{p} / \mathrm{or} / \mathrm{k} /)$ and the vowel parts $(/ \mathrm{a} /)$ of the syllables (see "fast" complex sounds described in Shtyrov et al., 2000b). The stimuli were presented in separate sessions counterbalanced across the subjects. The sound duration and the stimulus-onset asynchrony were 185 and 900 msec, respectively. The probabilities of $/ \mathrm{pa} /$ and $/ \mathrm{ka} /$, and their nonspeech equivalents, were 0.85 and 0.15 , respectively. All subjects perceived the speech sounds as proper syllables, and none of them reported perceiving phonetic content in the non-speech sounds. The perceptual categorization during the experiment was indexed by the lateralization of the mismatch fields evoked by the less frequent stimuli (Shtyrov et al., 2000b). Data shown here were extracted from the responses to the frequent stimuli (/pa/ and its non-speech equivalent), for which a minimum of 1000 epochs were averaged online. The sounds were delivered binaurally at $60 \mathrm{~dB}$ above the hearing threshold. Subjects were instructed to attend to a silent video film and to ignore auditory stimuli.

Data acquisition. Magnetic responses were recorded and averaged online with a 122-channel whole-scalp Neuromag-122 magnetoencephalography (MEG) system in a magnetically shielded room with a sampling rate of $600 \mathrm{~Hz}$. Epochs (from $200 \mathrm{msec}$ before stimulus onset to $350 \mathrm{msec}$ thereafter) with electro-oculogram or MEG values exceeding $150 \mu \mathrm{V}$ or $3000 \mathrm{fT} / \mathrm{cm}$, respectively, were excluded.

Data analysis. To represent the signal amplitude as a function of time and frequency, the evoked responses were filtered with Gabor wavelets $h(t, f) ; h(t, f)=k \exp \left(-x^{2} / 2+i m x\right), x=2 \pi f t / m$, where time and frequency are denoted by $t$ and $f$, respectively, $m=8, i=V^{-1}$, and $k$ is a normalization constant. The moduli of the complex-valued filter outputs represent the amplitude of the signal at narrow frequency bands as a function of time (Sinkkonen et al., 1995). The center frequency $f$ of the wavelet was varied in $1 \mathrm{~Hz}$ steps to cover the frequency range between 20 and $75 \mathrm{~Hz}$. The mean modulus of the prestimulus time from -150 to -50 msec was subtracted from the modulus of the whole signal separately at each frequency. For each subject, condition, and hemisphere, we averaged the time-frequency representations of the 10 channels with the largest amplitude maximum relative to the prestimulus level within 25-75 $\mathrm{Hz}$ and within $0-100 \mathrm{msec}$ from stimulus onset. We estimated the latency and amplitude of the amplitude maximum at each wavelet frequency, which gave a string of latency-amplitude pairs spanning the analyzed frequencies. The latency and amplitude values (see Fig. 2) were accepted for statistical analysis (one-way ANOVA) only when the peak amplitude exceeded the respective values of the prestimulus interval by at least 4 SDs in both hemispheres. Stimulus-hemisphere interactions were evaluated with two-way ANOVA. The results of the statistical analyses were not corrected for multiple statistical comparisons (55 tests in each graph of Fig. 2). The binomial probability $P$ for obtaining six false positives at the significance level $p<0.05$ or three at the level $p<0.01$ is $p<0.05$. The results did not change essentially with changes in the values of the $m$-parameter (6-9), the number of the selected channels (5-10), the peak-detection threshold (2-7 SD), or with the statistical test (ANOVA, paired $t$ test, Wilcoxon signed-rank test).

We also estimated the frequencies of the amplitude maxima from the latency-amplitude pairs (see Fig. 3). The peaks were accepted as above. To determine whether these frequencies were correlated, we paired the frequencies both across the hemispheres and across the conditions within one hemisphere. When more than one maximum was found within the response, the closest frequencies were paired, and nonpaired frequencies were omitted. To estimate the frequency-difference distribution, the distances of all frequency pairs from the diagonal were pooled into histograms. The confidence limits were estimated by shuffling the frequencies across the subjects, selecting the frequency pairs as above, and computing the histogram mean and SD for 1000 randomizations. The original and shuffled histograms were also compared with the $\chi^{2}$ goodness-of-fit test after appropriate rebinning.

The amplitudes and peak latencies of the low-frequency $(0.1-20 \mathrm{~Hz})$ evoked responses were estimated by conventional time-domain peak-bypeak analysis from the signal obtained by averaging the absolute values of the filtered $(0.1-20 \mathrm{~Hz})$ signals over the channels used for the analysis of the gamma-band responses.

\section{RESULTS}

The largest magnetic gamma responses to speech and non-speech sounds were always found in the channels over the temporal cortices, suggesting that they were generated within or in the vicinity of the auditory cortex (Pantev et al., 1991; Pantev and Elbert, 1994). We averaged time-frequency representations (TFRs) of the evoked responses in the 10 channels over each hemisphere with the largest gamma-band signal-to-noise ratios. The averaged TFRs revealed that the evoked responses had a large oscillatory component in the low-gamma band $(20-45 \mathrm{~Hz})$, and another in the high-gamma band (45-75 Hz) (Fig. 1). The high-gamma component was prevalent in the responses to the speech sound, particularly in the right hemisphere, but was also present in the responses to the non-speech sound (see also Fig. $3 A, B)$.

The intersubject variability in the number of oscillatory components and in the oscillation frequencies was considerable, as evidenced by the relatively smooth frequency distributions in the grand-averaged TFRs (Fig. 1; see also Fig. 3), although the oscillations in the individual subjects were concentrated on narrow frequency bands. Previous studies have relied on either the TFR peak energy and latency (Tallon-Baudry et al., 1996, 1997; Knief et al., 2000) or bandpass filtering of the data with an a priori determined filter (Pantev et al., 1991; Bertrand and Pantev, 1994; Pantev and Elbert, 1994; Tiitinen et al., 1994) to characterize the evoked gamma component. We analyzed the response in a frequency-dependent manner to account for both the possible presence of several gamma components and for the large intersubject variability in the response frequencies. We found highly significant differences in the hemispheric lateralization of the peak latency and amplitude that were constrained onto narrow frequency bands. The responses to the speech sound peaked earlier in the left than right hemisphere at both low $(27-42 \mathrm{~Hz}$; $p<0.001$ to $p<0.01$, one-way ANOVA) (Fig. 2, Materials and Methods) and high gamma frequencies $(59-68 \mathrm{~Hz} ; p<0.05)$. In contrast, the responses to the non-speech sound peaked earlier in the right than left hemisphere $(24-27 \mathrm{~Hz}, 48-52 \mathrm{~Hz} ; p<0.01$ to $p<0.05)$. The interhemispheric latency lateralization differed between speech and non-speech sounds at 23-31 Hz $(p<0.0001$ to $p<0.05$; two-way ANOVA), at $39-41 \mathrm{~Hz}(p<0.05)$, and at $50-68 \mathrm{~Hz}(p<0.001$ to $p<0.05)$. The response amplitude for the speech sound was similar in the two hemispheres at low gamma frequencies $(<45 \mathrm{~Hz})$, but higher in the right than in the left hemisphere at high $(>45 \mathrm{~Hz})$ gamma frequencies $(51-70 \mathrm{~Hz}$; $p<0.001$ to $p<0.05$; one-way ANOVA). For the non-speech sound the response amplitude was higher in the right hemisphere nearly throughout the gamma band $(26-31,35-58 \mathrm{~Hz} ; p<0.05)$. 

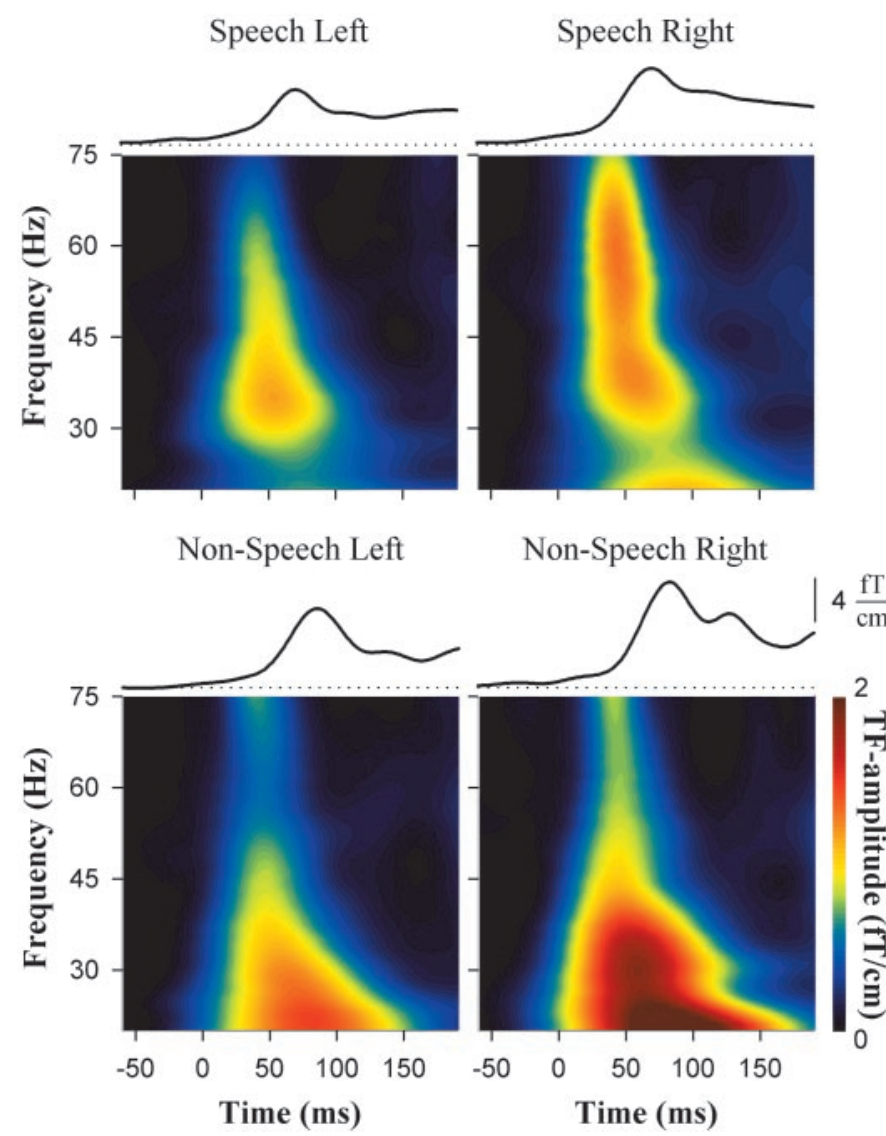

Figure 1. Grand-average TFRs and $0.1-20 \mathrm{~Hz}$ waveforms of the responses to speech and non-speech sounds, averaged over 10 temporal channels. An increase in the TF amplitude reflecting the evoked gamma oscillation is observed at $20-120 \mathrm{msec}$ from stimulus onset. The amplitude is color-coded; large amplitudes are denoted with red and small with blue. Note that the $0.1-20 \mathrm{~Hz}$ waveforms are an average over the absolute values of the evoked responses.

The interhemispheric amplitude lateralization differed between speech and non-speech sounds at $26-37 \mathrm{~Hz}(p<0.001$ to $p<$ 0.05; two-way ANOVA) and at 60-65 Hz $(p<0.05)$.

In contrast with the broad intersubject variability in the peak frequencies of the responses (Fig. $3 A$; see also Fig. 1), the frequencies were strongly correlated within individual subjects between the left and right hemispheres for both sounds $(p<0.01$; $\chi^{2}$ test) (Fig. 3B), and also between the sounds within each hemisphere $\left(p<0.0005 ; \chi^{2}\right.$ test) (Fig. $\left.3 C\right)$. Throughout the gamma band, the peak frequencies for the speech sound were slightly but consistently higher than the corresponding peak frequencies for the non-speech sound in both hemispheres (left, $2.7 \pm 0.9 \mathrm{~Hz}, p<0.003$; right, $1.7 \pm 0.9 \mathrm{~Hz}, p<0.03$; paired $t$ test) (Fig. $3 C$ ). We did not detect interhemispheric frequency differences either for the speech $(-0.2 \pm 1.0 \mathrm{~Hz} ; p>0.3)$ or for the non-speech sound $(-0.8 \pm 1.7 \mathrm{~Hz} ; p>0.4)$.

Finally, to determine whether the stimulus dependence was confined to the gamma frequencies, we estimated the amplitudes and peak latencies of the early low-frequency $(0.1-20 \mathrm{~Hz})$ responses (Fig. 1) (Shtyrov et al., 2000a). We found no interhemispheric differences in the peak latencies either for the speech sound (mean latency, $60 \pm 3 \mathrm{msec}$ for each hemisphere; $p>0.5$, paired $t$ test) or for the non-speech sound (mean latencies $66 \pm 3$ and $67 \pm 3 \mathrm{msec}$ for the left and right hemispheres, respectively;
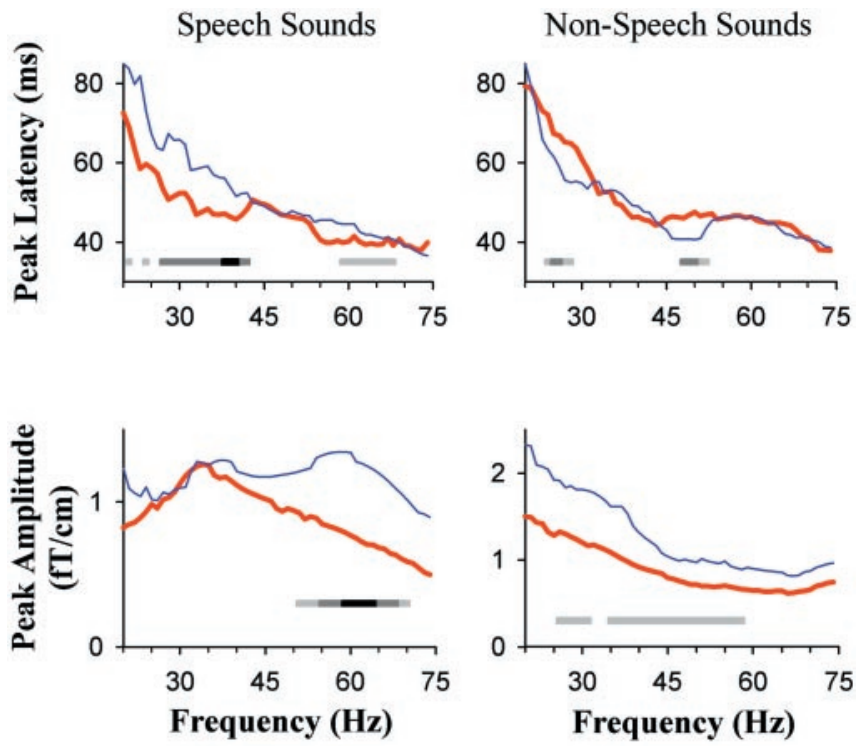

\section{- Right Hemisphere \\ - Left Hemisphere}

Figure 2. Interhemispheric lateralization of response latencies and amplitudes for speech and non-speech sounds in the gamma-frequency band. Thick red lines denote the peak latencies (top pair) and the amplitudes (bottom pair) of the left hemisphere, and thin blue lines those of the right hemisphere. The significance levels of the interhemispheric differences are indicated with horizontal bars (light gray, $p<0.05$; dark gray, $p<0.01$; black, $p<0.001)$.

$p>0.5)$. The response amplitude was larger in the right hemisphere for both the speech and non-speech sounds $(25-150 \mathrm{msec}$, $p<0.05$ for the speech sound; $30-80$ and $110-160$ msec, $p<0.05$ for the non-speech sound, one-way ANOVA). The left-rightamplitude ratios, however, were nearly identical for the two sounds (<300 msec; $p>0.2$; one-way ANOVA).

\section{DISCUSSION}

In the present study, speech and non-speech stimuli evoked gamma-band $(20-80 \mathrm{~Hz})$ responses with opposite latency lateralization and distinct amplitude and frequency characteristics at 40-60 msec from stimulus onset. We found no stimulus dependence in the latency or amplitude lateralization of the early low-frequency $(0.1-20 \mathrm{~Hz})$ responses, in particular the P50m wave peaking concurrently with the gamma response. These results suggest that the early gamma-band components of the evoked response are sensitive to high-level stimulus properties.

\section{Oscillatory characteristics of evoked gamma-band activity}

The frequency-band specificity of the latency and amplitude lateralization, the bimodality of the frequency distributions (Figs. 1, $3 A$ ), and the clustering of the frequency pairs (Fig. $3 B$ ) suggest that the evoked gamma response consists of at least two oscillatory components at low- and high-gamma frequencies. The differential patterns of amplitude lateralization suggest that the neural populations underlying the low- and high-gamma components may also have different functional roles. Taken together, these results imply that the evoked gamma response has characteristics of an oscillatory process. However, based on a large number of both intracranial and scalp recordings, the classical 

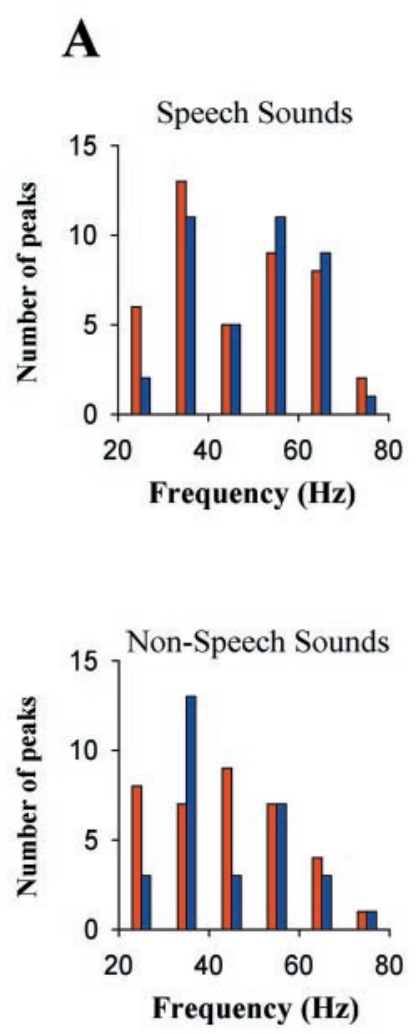
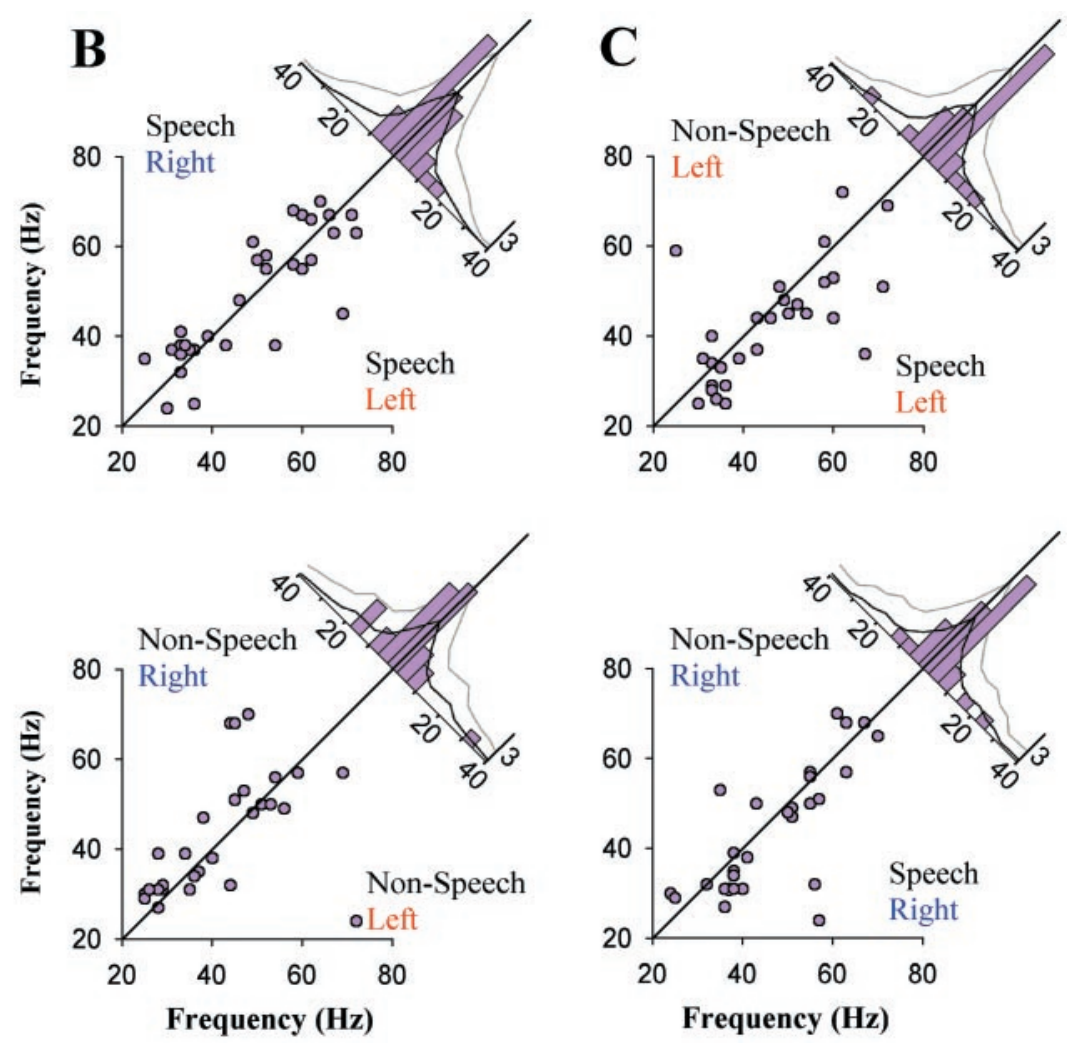

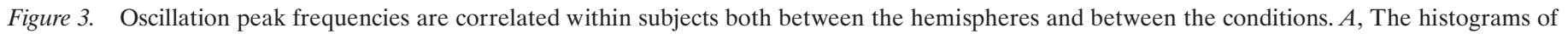

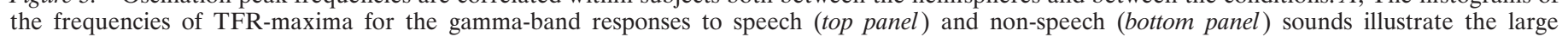

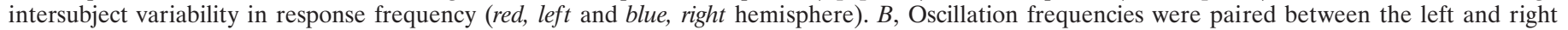

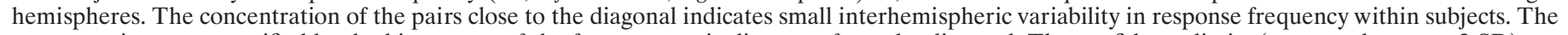

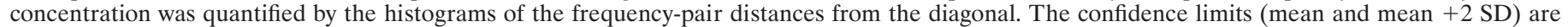

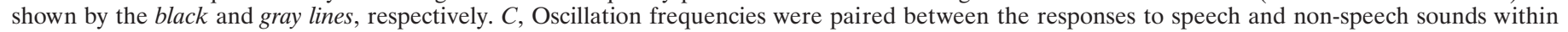

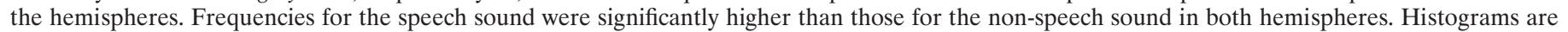
as in $B$.

view has been that the evoked gamma-band activity in scalp recordings is produced by spatial smearing of distinct auditory middle-latency components (MLCs) occurring at intervals corresponding to gamma-band rhythmicity. The MLCs are generated by a sequential and distributed activation of different auditory cortical areas, without stereotypical oscillations in any of these areas (Liegeois-Chauvel et al., 1994; Yvert et al., 2001).

With recordings from the rat auditory cortex, Sukov and Barth (1998) have shown that the neural populations activated asynchronously during the MLCs of the click-evoked auditory potential seem to be the same as those generating the evoked and spontaneous gamma oscillations. It thus appears plausible to consider the sequential activation of the MLCs in the human brain as a large-scale population oscillation. The oscillatory nature of this sequential activation could be organized by, e.g., reciprocal connections within the neocortex (Sukov and Barth, 2001) as well as between neocortex and thalamus (cf. Steriade et al., 1996).

\section{Shared characteristics of the evoked and induced gamma oscillations}

Whether the evoked gamma oscillations act as a dynamic grouping mechanism for feature binding, and thus for object representation, has remained unclear. Unlike the induced, the evoked gamma oscillations have been reported insensitive to several physical and cognitive stimulus properties (Pantev et al., 1991;
Bertrand and Pantev, 1994; Pantev and Elbert, 1994; Tiitinen et al., 1994; Tallon-Baudry et al., 1996, 1997; Eulitz et al., 2000; Haenschel et al., 2000). The sensitivity of evoked gamma oscillation to high-level stimulus properties in the present data, however, points to a similarity between the evoked and induced gamma components (cf. Tallon-Baudry et al., 1996; Knief et al., 2000). Supporting the concept of early dynamic grouping, Fries et al. (2001a) recently showed that stimulus-induced synchronization in vivo may occur in the latency range of the evoked gamma oscillations. Moreover, selective attention, guiding the isolation and representation of a target object among distractors, affects both the evoked (Tiitinen et al., 1993; Fries et al., 2001b) and induced gamma responses (Tallon-Baudry et al., 1997). Thus, the evoked and induced gamma oscillations are similar in being sites for both bottom-up integration and top-down modulation.

\section{Putative roles of evoked gamma oscillations in speech processing}

Several recent studies support the presence of distinct speechspecialized networks in the human brain (Binder et al., 1997; Galuske et al., 2000). Näätänen et al. (1997) reported the existence of cortical language-specific memory traces for speech sounds whose activation is reflected in the mismatch negativity that occurs 100-150 msec from stimulus onset and is based on integrated sound representations (for review, see Näätänen and Winkler, 1999). These traces are formed within the first year of 
life (Cheour et al., 1998) and have been hypothesized to underlie the activation of the speech-specialized network in the left hemisphere. Whereas, in our data, the amplitudes of all other early components of the evoked response were greater in the right than in the left hemisphere for both speech and non-speech sounds, the lack of right-hemispheric amplitude lateralization in the lower gamma band for speech sounds may reflect the activation of the left-hemispheric speech-specialized network (cf. Pulvermüller et al., 1996). However, because of the complexity of the response patterns of the evoked gamma oscillation, its specific roles in the early language processing require further investigations.

\section{Emergence of early and late neural representations}

The present data raise the possibility that templates of feedforward connections (cf. Singer, 1995; Tsodyks et al., 1999) might contribute to feature binding during the evoked gamma oscillation for frequently and naturally occurring feature constellations and objects belonging to cognitive categories learned during early development (Singer, 1995; Cheour et al., 1998). In our framework, an early neural representation would be distributed over the two to four evoked gamma cycles nested in the underlying low-frequency oscillation and integrated over time, in accordance with the concept of the sequential activation of cortical areas. We propose that stimulus representations are elaborated iteratively so that the neural activity following stimulus presentation is parsed into alternating representational and non-representational stages, reflected in alternating large-scale bursts of gamma oscillations (either evoked or induced) and low-frequency components.

\section{REFERENCES}

Alku P, Tiitinen H, Näätänen R (1999) A method for generating natural-sounding speech stimuli for cognitive brain research. Clin Neurophysiol 110:1329-1333.

Assadollahi R, Pulvermüller F (2001) Neuromagnetic evidence for early access to cognitive representations. NeuroReport 12:207-213.

Bertrand O, Pantev C (1994) Stimulus frequency dependence of the transient oscillatory auditory evoked responses $(40 \mathrm{~Hz})$ studied by electric and magnetic recordings in humans In: Oscillatory eventrelated brain dynamics (Pantev C, Elbert T, Lütkenhöner B, eds), pp 231-242. New York: Plenum.

Binder JR, Frost JA, Hammeke TA, Cox RW, Rao SM, Prieto T (1997) Human brain language areas identified by functional magnetic resonance imaging. J Neurosci 17:353-362.

Castelo-Branco M, Goebel R, Neuenschwander S, Singer W (2000) Neural synchrony correlates with surface segregation rules. Nature 405: $685-689$.

Cheour M, Ceponiene R, Lehtokoski A, Luuk A, Allik J, Alho K, Näätänen R (1998) Development of language-specific phoneme representations in the infant brain. Nat Neurosci 5:351-353.

Eulitz C, Eulitz H, Maess B, Cohen R, Pantev C, Elbert T (2000) Magnetic brain activity evoked and induced by visually presented words and nonverbal stimuli. Psychophysiology 37:447-455.

Fries P, Neuenschwander S, Engel AK, Goebel R, Singer W (2001a) Rapid feature selective neuronal synchronization through correlated latency shifting. Nat Neurosci 2:194-200.

Fries P, Reynolds JH, Rorie AE, Desimone R (2001b) Modulation of oscillatory neuronal synchronization by selective visual attention. Science 291:1560-1563.

Galuske RA, Schlote W, Bratzke H, Singer W (2000) Interhemispheric asymmetries of the modular structure in human temporal cortex. Science 289:1946-1949.

Gray CM (1999) The temporal correlation hypothesis of visual feature integration: still alive and well. Neuron 24:31-47.

Haenschel C, Baldeweg T, Croft RJ, Whittington M, Gruzelier J (2000) Gamma and beta frequency oscillations in response to novel auditory stimuli: a comparison of human electroencephalogram (EEG) data with in vitro models. Proc Natl Acad Sci USA 97:7645-7650.

Knief A, Schulte M, Bertrand O, Pantev C (2000) The perception of coherent and non-coherent auditory objects: a signature in gamma frequency band. Hear Res 145:161-168.

Linkenkaer-Hansen K, Palva JM, Sams M, Hietanen JK, Aronen HJ, Ilmoniemi RJ (1998) Face-selective processing in human extrastriate cortex round $120 \mathrm{~ms}$ after stimulus onset revealed by magneto- and electroencephalography. Neurosci Lett 253:147-150.

Liegeois-Chauvel C, Musolino A, Badier JM, Marquis P, Chauvel P (1994) Evoked potentials recorded from the auditory cortex in man: evaluation and topography of the middle latency components. Electroencephalogr Clin Neurophysiol 92:204-214.

Lutzenberger W, Pulvermüller F, Birbaumer N (1994) Words and pseudowords elicit distinct patterns of $30-\mathrm{Hz}$ EEG responses in humans. Neurosci Lett 176:115-118.

Näätänen R, Winkler I (1999) The concept of auditory stimulus representation in cognitive neuroscience. Psychol Bull 125:826-859.

Näätänen R, Lehtokoski A, Lennes M, Cheour M, Huotilainen M, Iivonen A, Vainio M, Alku P, Ilmoniemi RJ, Luuk A, Allik J, Sinkkonen J, Alho K (1997) Language-specific phoneme representations revealed by electric and magnetic brain responses. Nature 385: 432-434.

Palva S, Shtyrov Y, Kujala T, Palva JM, Ilmoniemi RJ, Näätänen R (2000) Syllables and complex sounds evoked distinct phase-locked gamma responses. Eur J Neurosci 12:168.

Pantev C, Elbert T (1994) The transient auditory evoked gamma band field In: Oscillatory event-related brain dynamics (Pantev C, Elbert T, Lütkenhöner B, eds), pp 219-230. New York: Plenum.

Pantev C, Makeig S, Hoke M, Galambos R, Hampson S, Gallen C (1991) Human auditory evoked gamma-band magnetic fields. Proc Natl Acad Sci USA 88:8996-9000.

Pulvermüller F, Assadollahi R, Elbert T (2001) Neuromagnetic evidence for early semantic access in word recognition. Eur J Neurosci 13:201205.

Pulvermüller F, Eulitz C, Pantev C, Mohr B, Feige B, Lutzenberger W, Elbert T, Birbaumer N (1996) High-frequency cortical responses reflect lexical processing: an MEG study. Electroencephalogr Clin Neurophysiol 98:76-85.

Rodriguez E, George N, Lachaux JP, Martinerie J, Renault B, Varela FJ (1999) Perception's shadow: long-distance synchronization of human brain activity. Nature 397:430-433.

Singer W (1995) Development and plasticity of cortical processing architectures. Science 270:758-764.

Singer W (1999) Neuronal synchrony: a versatile code for the definition of relations? Neuron 24:49-65.

Singer W, Gray CM (1995) Visual feature integration and the temporal correlation hypothesis. Annu Rev Neurosci 18:555-586.

Sinkkonen J, Tiitinen H, Näätänen R (1995) Gabor filters: an informative way for analysing event-related brain activity. J Neurosci Methods 56:99-104.

Shtyrov Y, Kujala T, Lyytinen H, Ilmoniemi RJ, Näätänen R (2000a) Auditory cortex evoked magnetic fields and lateralization of speech processing. NeuroReport 11:2893-2896.

Shtyrov Y, Kujala T, Palva S, Ilmoniemi RJ, Näätänen R (2000b) Discrimination of speech and complex non-speech sounds of different temporal structure in the left and right cerebral hemispheres. NeuroImage 12:657-663.

Steriade M, Contreras D, Amzica F, Timofeev I (1996) Synchronization of fast $(30-40 \mathrm{~Hz})$ spontaneous oscillations in intrathalamic and thalamocortical networks. J Neurosci 16:2788-2808.

Sukov W, Barth DS (1998) Three-dimensional analysis of spontaneous and thalamically evoked gamma oscillation in auditory cortex. J Neurophysiol 79:2875-2884.

Sukov W, Barth DS (2001) Cellular mechanisms of thalamically evoked gamma oscillations in auditory cortex. J Neurophysiol 85:1235-1245.

Tallon-Baudry C, Bertrand O (1999) Oscillatory gamma activity in humans and its role in object representation. Trends Cogn Sci 3:151-162.

Tallon-Baudry C, Bertrand O, Delpuech C, Pernier J (1996) Stimulus specificity of phase-locked and non-phase-locked $40 \mathrm{~Hz}$ visual responses in human. J Neurosci 16:4240-4249.

Tallon-Baudry C, Bertrand O, Delpuech C, Pernier J (1997) Oscillatory $\gamma$-band $(30-70 \mathrm{~Hz})$ activity induced by a visual search task in humans. J Neurosci 17:722-734.

Tiitinen H, Sinkkonen J, Reinikainen K, Alho K, Lavikainen J, Näätänen $\mathrm{R}$ (1993) Selective attention enhances the auditory $40-\mathrm{Hz}$ transient response in humans. Nature 364:59-60.

Tiitinen H, Sinkkonen J, May P, Näätänen R (1994) The auditory transient $40-\mathrm{Hz}$ response is insensitive to changes in stimulus features. NeuroReport 6:190-192.

Thorpe S, Fize D, Marlot C (1996) Speed of processing in the human visual system. Nature 381:520-522.

Tsodyks M, Kenet T, Grinvald A, Arieli A (1999) Linking spontaneous activity of single cortical neuron and the underlying functional architecture. Science 286:1943-1946.

Yvert B, Crouzeix A, Bertrand O, Seither-Preisler A, Pantev C (2001) Multiple supratemporal sources of magnetic and electric auditory evoked middle latency components in humans. Cereb Cortex 11:411423 . 